\title{
La pedagógica de la liberación de Enrique Dussel: Inakayal y lo que la pedagogía nos negó
}

\section{- Nadia Heredia}

\section{Resumen}

La Pedagógica dusseliana se desprende de la primera relación ética, que es el cara-acara. Esta relación se da en determinado sistema ideológico (Totalidad) que es el que selecciona lo que se transmite de una generación a otra, el legado educativo-cultural.

\section{Palabras clave:}

Filosofía de la liberación, Dussel, pedagógica, Inakayal.

Lo que Dussel hace en la Pedagógica es repensar esta relación cara-a-cara a partir de las formas de dominio que inaugura la llegada de los españoles en 1492 al territorio Latinoamericano, donde "el varón conquistador se transformó en padre opresor, en maestro dominador" (1980, p. 18). Ética y política se constituyen aquí en aspectos indisociables para repensar desde la filosofía de la liberación las relaciones de dominio que van desde el plano erótico familiar (madre-padre/hijx), al plano político institucional (maestrx/estudiante).

Ahora bien, ¿qué lugar ocupa en nuestras constituciones subjetivas el origen de dominación y opresión que portamos a partir de 1492? ¿En qué medida esta primera relación ética, transformada en relación de dominio y negación condiciona nuestras formas de posicionarnos geopolíticamente en esta distribución impuesta del sistema-mundo universal?

En este trabajo, analizaré la vigencia crítica de los principios ético-políticos que dan origen a la pedagógica de la liberación de Enrique Dussel para resignificarlos en la postulación de una educación que revalorice lo históricamente excluido. La historia del cacique Tehuelche Inakayal, será la que dé contenido a la Pedagógica dusseliana, como parte de una reflexión ético-política de liberación situada, desde la Patagonia Argentina. 


\section{Enrique Dussel's pedagogical of liberation: Inakayal and what the pedagogy denied us}

\begin{abstract}
Keywords:
Philosophy of liberation, Dussel, pedagogical, Inakayal.
\end{abstract}

\begin{abstract}
Dusselian's Pedagogical emerges from the first ethical relationship, which is the faceto-face. This relationship occurs in a certain ideological system (Totality) which is what selects what is transmitted from one generation to another, the educational-cultural legacy.

What Dussel does in his Pedagogical is to rethink this face-to-face relationship from the forms of domination that inaugurated the arrival of Columbus in 1492 to the Latin American territory, where "the conquering man became an oppressive father, a dominating teacher" (1980, p. 18). Ethics and politics are constituted here in inseparable aspects to rethink from the theoretical framework of philosophy of liberation the relations of domination that go from the family erotic plane (mother-father/son), to the institutional political plane (teacher/student). What place occupies in our subjective constitutions the origin of domination and oppression that we carry from 1492 ? How does it influence us that this first ethical relationship has been transformed into a relationship of domination and denial? Does it condition our ways of geopolitical positioning ourselves in this imposed distribution of the universal world-system?

In this paper, I will analyze the critical validity of the ethical-political principles that give rise to the pedagogical of Enrique Dussel's release to resignify them in the postulation of an education that revalues the Other historically excluded. The story of Chief Tehuelche Inakayal, will be the one that give us the content to apply the Dusselian Pedagogical categories, as part of an ethical-political reflection of liberation situated, from the Argentine Patagonia.
\end{abstract}

\section{Partir del origen}

Inicio estas páginas intentando llegar aún más allá de mis palabras. Inicio este recorrido intentando escuchar y escucharme en las voces de otras generaciones. Generaciones que me antecedieron, que me han posicionado hoy en los lugares que estoy y que soy, siempre propensos a su transformación. Inicio esta reflexión pensando en mis abuelas, en mis orígenes, en las mujeres que me conforman. Mujeres por las cuales soy.

Mestiza de manual: mitad de las raíces mapuces, la otra mitad española. El pueblo nación mapuce se hallaba localizado al sur de América del Sur, antes de la llegada de los españoles. Fueron corridxs primero por los incas en su expansión territorial y luego por los Estados Nacionales en los genocidios militares llevados a cabo en el Siglo XIX en Argentina y Chile bajo el nombre de Conquista del desierto y Ocupación de la Araucanía, respectivamente. Mi familia materna, que vivía al sur de lo que hoy es la provincia de Buenos Aires, quedó localizada a más de mil quinientos kilómetros de distancia, en la Patagonia argentina, como resultado de la huida. Sobrevivieron comiendo piñones, el fruto de la araucaria, en cuevas de una ciudad llamada Aluminé. Eso cuenta mi madre, que le contó su abuela.

Del otro lado de mi historia, están lxs abuelxs corridxs por el hambre de la posguerra europea. Abuelxs españoles de Córdoba, que buscando quizás alguna cercanía con lo que se dejaba atrás, con lo perdido, eligieron instalarse en un lugar homónimo de Argentina, la provincia de Córdoba. De allí, mi abuela paterna, la historia de un tío 
mulato porque su mamá era de descendencia africana y una tía abuela que dicen que viajó con muchos libros. Eso cuenta mi padre. Mi abuela paterna, de descendencia directa española se llamaba María y, por supuesto, así también me llamaron.

Pensando en qué compartirles en estas líneas, la resignificación de las categorías dusselianas propuestas en su pedagógica de la liberación resuenan en mí como un horizonte y un punto de partida. Inmersa en un entramado ético-político, la Pedagógica es postulada por Dussel como una de las primeras experiencias humanas que se da sujeto a sujeto, él lo denomina, retomando a Levinas, el encuentro cara-a-cara. Es una relación generacional y, por eso mismo, es el puente que me permitirá establecer nexos entre las Totalidades, entendidas como sistemas, que compartimos con las generaciones que me anteceden.

Pienso en mis abuelas, pienso en mis orígenes, y me pregunto: ¿Qué relaciones establecer dentro de la Totalidad que nos tocó vivir? ¿Qué diálogos entablar para resituar una pedagógica de liberación situada, en términos dusselianos? ¿Qué cuestionamientos podría plantearle hoy a ese sistema de Totalidad desde las categorías de un marco teórico crítico, como es la filosofía de la liberación dusseliana? ¿Qué emergería de lo históricamente negado, en-cubierto, desde este planteo de la pedagógica?

En las páginas que siguen, situaré el surgimiento de la filosofía de la liberación como movimiento filosófico, para que se entienda luego la especificidad del planteo dusseliano de la pedagógica de la liberación. Establecidos estos marcos categoriales, analizaré los puntos centrales de los principios ético-políticos que dan origen a la pedagógica de la liberación de Enrique Dussel, para resignificar cuáles serían sus aportes para recrear hoy una educación no eurocéntrica y a la vez transmoderna, que nos resitúe en un contexto histórico crítico o, al menos, filosóficamente problematizado. Empecemos entonces.

Para situar a modo de introducción, tanto la filosofía de la liberación ${ }^{1}$ dusseliana, como su pedagógica de la liberación, iniciaré destacando que ambas tienen su origen en un momento histórico donde reflexionar sobre la dupla liberación y dependencia como una tarea urgente y necesaria en las academias y la intelectualidad Latinoamericana. No obstante, antes de avanzar, vale aquí una aclaración. La obra de Dussel es basta en las temáticas que aborda. Tal como él mismo la ha pensado, se articula en lo que da en llamar una arquitectónica, que es, una estructura teórica que va entramando etapas de su pensamiento, como un desarrollo lógico de momentos del ser, siempre pensado geopolíticamente. Es decir, historia, ética, política, se van entramando en un recorrido filosófico que inicia con profundos debates con los clásicos europeos, de los cuales poco a poco se va desprendiendo, hasta poder iniciar sus propios caminos de liberación, tal como él mismo los llama, en alusión a su posicionamiento Latinoamericano. En este sentido $-\mathrm{y}$ de todas las posibilidades desde las que podría plantear el necesario recorte para una breve introducción al enfoque dusseliano de la FL-, el punto que considero relevante es el que resalta la influencia del contexto histórico-político de su pensamiento. Es decir, el contexto geopolítico.

A principio del Siglo XX, a través de las experiencias revolucionarias latinoamericanas, la "liberación" se transforma en una posibilidad concreta. En 1910, se produce el triunfo de la rebelión agraria liderada por Emiliano Zapata que abate al dictador Porfirio Díaz en México. En 1959, la Revolución cubana liderada por Fidel Castro y Ernesto Guevara destituye al dictador Fulgencio Batista. Estos son algunos de los antecedentes históricos que, tanto la FL como otras disciplinas del campo de las ciencias sociales, toman como referencia para reflexionar críticamente acerca de las posibilidades históricas concretas de trazar un rumbo distinto al delineado por los poderes político-económicos entonces imperantes. 
En Latinoamérica y el Caribe lxs oprimidxs se levantan enfrentando las injusticias de los sistemas opresores, y triunfan. Y este hecho no es tomado como una experiencia más en el devenir histórico, sino más bien como una ruptura capaz de torcer los destinos coloniales prefijados desde afuera, dirá Dussel (1992). En este contexto, argumentar filosóficamente el rol transformador de lxs sujetos históricamente oprimidxs de la historia se convierte en una de las tareas fundamentales que atraviesa todos los discursos de la Filosofía latinoamericana del Siglo XX y el de la FL en particular. Debates como el sostenido por importantes referentes como Leopoldo Zea, desde México; o Salazar Bondy, en Perú, plantean la necesidad de la autenticidad de un pensamiento latinoamericano frente a la universalidad impuesta por el occidente. Pensar si es posible la existencia de una Filosofía latinoamericana, genera un contexto crítico donde el horizonte de debate es postulado con claridad y contundencia: o se hace filosofía copiando o se hace filosofía desde lo propio, aún cuestionando lo que propio signifique. La Filosofía, si piensa, deberá pensar desde sus propios términos, desde su propia realidad:

La filosofía [...] porque es reflexión sobre su propia realidad parte de lo que ya es, de su propio mundo, de su sistema, de su espacialidad. Lo cierto es que pareciera que la Filosofía ha surgido siempre en la periferia, como necesidad de pensarse a sí misma ante el centro y ante la exterioridad total, o simplemente ante el futuro de liberación. (Dussel, 1977a, p. 15)

En este sentido, ya en la década de 1970, la FL se sitúa en un punto de partida político e ideológico fundacional distinto. Desde un principio, "no pretende pensar solo las condiciones de posibilidad de una filosofía latinoamericana. Ella es desde su comienzo, filosofía latinoamericana" (Dussel, 1973, p. 11).

Tomando como antecedentes teóricos la Teoría de la Dependencia, de Cardoso y Faletto (1969), y la Teología de la Liberación, de Gustavo Gutiérrez (1971), la FL toma al sujeto latinoamericano a partir de su dolor sacrificial inicial, es decir, inmerso en las relaciones de dominio político, económico, erótico y pedagógico -en tanto culturales- que dan inicio en 1492, momento en el que Dussel plantea que surge realmente la modernidad. La FL se convierte así en la primera experiencia de un movimiento filosófico que pone de relevancia la figura del Otro históricamente oprimido por fuera de la ontología, resituándolo a partir de las mediaciones como centro de un proyecto filosófico de Liberación:

Hasta este momento nuestro discurso ha sido como un resumen de lo ya sabido. Desde ahora comienza un nuevo discurso, que cuando sea implantado en su nivel político correspondiente y con las mediaciones necesarias, [...] podremos ahora sí decir que es un nuevo discurso en la historia de la filosofía mundial. Esto no se debe a nuestra poca o mucha inteligencia, se debe a que simplemente cuando nos volvemos a la realidad, como exterioridad, por el solo hecho de ser una realidad histórica nueva, la filosofía que de ella se desprende, si es auténtica, no podrá menos que ser igualmente nueva. Es la novedad de nuestros pueblos lo que se debe reflejar como novedad filosófica y no a la inversa. (Dussel, 1977a, p. 55)

Crítica de los discursos filosóficos que toman a Grecia como origen y a Europa como centro, la FL postula la necesidad de partir de un pensamiento geopolíticamente situado, es decir, un pensar que reflexiona la realidad desde la periferia como fundamento de sentido. Si la filosofía europea que Latinoamérica replicaba era básicamente ontológica y metafísica, la FL debía diferenciarse desde estos nuevos horizontes reflexivos. Debía pronunciarse desde la exterioridad que denuncia:

Contra la ontología clásica del centro, desde Hegel hasta Marcuse, por nombrar lo más lúcido de Europa, se levanta una filosofía de la liberación de la periferia, de los 
oprimidos, la sombra que la luz del ser no ha podido iluminar. Desde el no-ser, la nada, el otro, la exterioridad, el misterio de lo sin-sentido, partirá nuestro pensar. Es entonces, una “filosofía bárbara”. (Dussel, 1977a, p. 26)

Si bien la deconstrucción que Dussel realiza del pensar ontológico y metafísico europeo es exhaustiva, no profundizaremos este punto. Pero cabe aclarar que es en este momento en el que la FL se posiciona como discurso emergente por fuera del discurso hegemónico europeo. Partiendo de la "experiencia originaria del descubrimiento del 'hecho' masivo de la dominación” (Dussel, 1998, p. 20), las categorías centrales de la filosofía y la ética levinasiana permiten incorporar desde un rol protagónico a los sujetos históricamente excluidxs, y este es el principal interés de la FL de las historias oficializadas. Es en este contexto, y otros de no menor complejidad, que Dussel se pregunta y nos interpela “ ¿ $S e$ dan cuenta de que la filosofía no es una tarea impersonal y cómoda, sino un deber muy grave?” (Dussel, 1977b, p. 72).

\section{La geopolitización de la filosofía como sustento de la pedagógica de la liberación}

Tal como se mencionó anteriormente, Levinas es quien aporta la base categorial que la FL utiliza para "politizar la ontología" (Dussel, 1993, p. 142) La reinterpretación levinasiana de categorías como Totalidad, Otredad, Exterioridad, entre otras, desde las experiencias latinoamericanas de opresión y dominio, se tornan centrales para argumentar la Pedagógica como una vuelta en contexto a nuestras historias negadas. Veremos el porqué de su relevancia.

Precisamente, la noción de Otro que plantea Levinas como aquel que queda fuera del sistema, o de todo orden entendido como una Totalidad, es una de las categorías éticas centrales que recupera la FL latinoamericana. Entendiendo Totalidad como todo sistema que cerrado sobre sí mismo genera inclusiones de lo Mismo, y exclusiones de lo distinto, el Otrx es el que está situado en la exterioridad de este sistema. El Otrx, es quien queda fijado más allá, externo, extranjero a lo que es considerado lo Mismo.

De esta forma, si en la ética levinasiana el Otrx negado es el pobre, la viuda o el oprimido, desde Latinoamérica la Otredad cobra materialidad en los múltiples rostros amerindios sistemáticamente negados. "En-cubiertos", dirá Dussel (1994) en su obra $1492 \ldots$, el encubrimiento del Otro, en clara respuesta a la construcción históricopolítica que enfatiza el hecho de un descubrimiento de Latinoamérica por parte de los españoles.

Es esta perspectiva levinasiana la que permite a esta generación de filósofxs que conforman el movimiento de la FL en general, y a Enrique Dussel en particular, ligar la filosofía con la realidad política desde lxs oprimidxs:

Hasta este momento nuestro discurso ha sido como un resumen de lo ya sabido. Desde ahora comienza un nuevo discurso, que cuando sea implantado en su nivel político correspondiente y con las mediaciones necesarias, que faltan en los filósofos del centro que usan estas mismas categorías, podremos ahora sí decir que es un nuevo discurso en la historia de la filosofía mundial. (Dussel, 1977, p. 55)

Poner de manifiesto el nexo de lo ético con el nivel de lo político, con las mediaciones necesarias, es lo que Dussel creativamente realiza a través de una lectura geopolítica de las categorías éticas levinasianas. 
Si la FL toma la ética como punto de partida, la política se torna necesaria para explicar los motivos filosóficos que encubren y justifican la dominación de América Latina (García Ruiz, 2014, p. 228). Es decir, para Dussel la interpelación del Otro a la Totalidad, desde la exterioridad, es la irrupción del Otro negado en nuestra historia amerindia:

El otro, absolutamente otro, de Levinas es concretizado por medio de la analogía: el otro es el indio empobrecido, el negro segregado, el judío exterminado, el africano y asiático discriminado, la mujer como objeto sexual, el niño o el joven manipulado por una educación ideológica, etcétera. (García Ruiz, 2014, p. 229)

A partir de esta reinterpretación dusseliana, la tarea de la filosofía se vuelve urgente: se trata de ser por fuera de que nos dijeron que éramos. Se trata de pensarnos, pero también de sentirnos, de mirarnos, de escucharnos, de empezar a hablarnos desde nuestras voces, a sabiendas que esa construcción ya es lo suficientemente compleja como para hacernos caer en el simplismo de un "nosotrxs", siempre ficticio. Se trata de:

... volvemos a la realidad, como exterioridad, por el solo hecho de ser una realidad histórica nueva, la filosofía que de ella se desprende, si es auténtica, no podrá menos que ser igualmente nueva. Es la novedad de nuestros pueblos lo que se debe reflejar como novedad filosófica y no a la inversa. (Dussel, 1977, p. 55)

Volvernos a la realidad como exterioridad, como novedad. Irrumpir el orden establecido y de lo establecido. Eso es precisamente lo que genera la irrupción de una nueva voz, nuestra voz, desde enunciaciones propias. Es, en alguna medida, la irrupción de lo político (en una Totalidad Otra, comprendida desde otros abordajes geopolíticos e históricos) en el plano de lo ético (que parte del reconocimiento de la voz de todo Otro negado).

De acuerdo con la FL dusseliana, hay tres tipos de relaciones sujeto-sujeto: la primera experiencia es la erótica, la segunda relación es la pedagógica y la tercera es la política. La pedagógica de la liberación es uno de los tres tipos de relación sujeto-sujeto que Dussel desarrolla. Es la relación que se da entre una generación y otra, entre lo que está y lo porvenir, siempre dentro de un sistema, es decir, dentro de una determinada Totalidad. Veremos en lo que sigue de qué forma estos tres niveles están intrínsecamente relacionados.

\section{La pedagógica como propuesta y crítica de la pedagogía moderna}

Pues bien, para abordar la Pedagógica dusseliana, el tema central de este trabajo, partiré de una vivencia personal. Una situación que me interpeló desde la enorme injusticia que rodeaba toda la sucesión de hechos que comentaré a continuación.

Tal como sucede con los encuentros que se dan entre Moctezuma y Cortés a partir de 1492 en los relatos que Dussel nos trae en sus obras, también consta en los archivos oficiales que los militares fueron tratados con hospitalidad en sus primeras expediciones a los territorios de los pueblos originarios del sur de Argentina. Este fue precisamente el caso del encuentro entre el cacique Inakayal, tal como lo nombran los documentos de la época, y el militar conocido como Perito Moreno. ${ }^{2}$

Inakayal era una autoridad en su comunidad tehuelche, situada al norte de la provincia de Chubut, y en el año 1879 conoce al Perito Moreno. Este ya formaba parte del ejército que llevaba adelante el proceso de ocupación de los territorios que pertenecían a los pueblos originarios, impulsada por el entonces presidente Julio Argentino 
Roca. Denominada Conquista del desierto, esta ocupación militar y corrimiento de las comunidades originarias hacia zonas en aquel entonces inhóspitas de la cordillera de los Andes, se realizó entre los años 1878 y 1879, en toda la extensión de lo que se conoce como Patagonia, al sur de Argentina.

Sobre Inakayal se cuenta que, en el año 1884, ya finalizada la Conquista del desierto, es capturado como prisionero cuando voluntariamente se presenta ante el comandante Lasciar para negociar la situación de sus territorios, ubicados ahora en las cercanías del Lago Nahuel Huapi, actual provincia de Río Negro.

Cuentan también que tras su captura es llevado, junto a su familia y otrxs caciques, a la isla Martín García, en la provincia de Buenos Aires, donde todxs son obligados a realizar trabajo forzado. Y que es precisamente en retribución a la hospitalidad ofrecida por Inakayal al Perito Moreno, este lo "rescata" de este destino pidiendo su trasladado al Museo de Ciencias Naturales de la ciudad de La Plata.

Allí eran exhibidxs como rarezas. De noche dormían todxs juntxs en un sótano cerrado con candados, donde recibían la comida. De día debían mantener limpio el lugar, realizar tareas que iban desde la creación de tejidos por parte de las mujeres, hasta la construcción del propio edificio del Museo, por parte de los hombres. Obviamente, y sobre todo por ser un museo, también formaba parte de las obligaciones cotidianas el dejarse retratar, pintar, observar y hasta tocar por lxs adeptxs visitantes del Museo.

Vivían en medio de restos óseos animales y humanos, pero el horror no termina allí. A medida que iban muriendo, rápidamente el personal del museo hacía su trabajo y lxs muertxs pasaban a ser exhibidxs en las vitrinas del lugar. O más bien, sus restos óseos. Así Inakayal vio morir a muchxs de sus familiares y a otrxs compañerxs capturadxs, para verlxs luego exhibidxs a través de un vidrio.

Allí, más que vivir tras el "rescate", iban muriendo. Inakayal aguantó semejante tortura por dos años, que seguramente le deben haber parecido siglos. Todo fue demasiado. Está registrado que en septiembre de 1888 Inakayal se suicidó. Antes de morir pronunció palabras en su lengua, que nadie entendió. Miró al cielo y luego un largo rato al sur del que fue arrancado, para finalmente tirarse escaleras abajo en el Museo de La Plata.

Pero la historia de Inakayal no termina ahí. Recién en el año 2001, a través de la Ley 25517 impulsada por el gobierno del presidente Néstor Kirchner, se establece en Argentina que: “[...] deberán ser puestos a disposición de los pueblos indígenas y/o comunidades de pertenencia que lo reclamen, los restos mortales de aborígenes, que formen parte de museos y/o colecciones públicas o privadas" (Ley 25517, 2010).

Es así como en el año 2006 antropólogxs forenses abocadxs a las tareas de restitución de identidades que aún hoy atraviesan la Argentina, pudieron identificar restos de Inakayal, que fueron restituidos a su comunidad recién en el año 2014. Casi ciento treinta años después.

Pues bien, hasta ahí el relato sobre Inakayal. En las páginas que siguen, para desarrollar las categorías centrales de la pedagógica de la liberación dusseliana, la relacionaré con algunos elementos de análisis que se desprenden de la historia de Inakayal.

Dussel plantea que lo pedagógico, a diferencia de la invención que es lo que se descubre por sí mismo, tiene que ver con otrxs, y más específicamente con lo que recibimos de otrxs. Es decir, como miembros de una comunidad nos conformamos en un entramado de relaciones históricas, éticas y políticas, y a través de lo pedagógico ofrecemos a otras 
generaciones aquello que consideramos fundante para definirnos social y comunitariamente. Nacemos por Otrxs y de Otrxs, y este hecho establece en el plano ético la primera relación que Dussel llama cara-a-cara. La segunda relación que establecemos sujeto-sujeto, para Dussel, es la Pedagógica y la tercera la Política.

Como se puede observar, este enfoque difiere de la definición clásica de Pedagogía, entendida como la disciplina que aborda los temas referidos a la enseñanza o el aprendizaje. Para Dussel, la pedagogía en sus formulaciones clásicas no ha tomado en cuenta ni problematizado el entramado de relaciones de dominio que van desde el plano erótico familiar (madre-padre/hijx), al plano político institucional (maestrx/estudiante). En este sentido, la pedagogía clásica omite problematizar que en el mundo cultural amerindiano marcado por la conquista del europeo "el varón conquistador se transformó en padre opresor, en maestro dominador" (Dussel, 1980, p. 18). La Pedagógica dusseliana se presenta así, como una crítica a las relaciones de dominio que establecemos entre sujetos desde un anclaje histórico y, sobre todo, desde una perspectiva amerindia.

La historia de la captura de Inakayal, como resultado de la llamada Conquista del Desierto, sucede casi cuatro siglos después de lo que Dussel denominó como encubrimiento de América, en 1492, y, sin embargo, también es un proceso militar hoy considerado como genocida. De hecho, reproduce la misma lógica de exterminio sistemático, con pretensión de dominio y opresión económica y política de lo que quede. Tal como sucedió en 1492, todo y todxs quienes fueron encontrados en el embate militar expansionista fue negado, cuando no, eliminado. Al punto de llamar "conquista" al robo y la usurpación territorial blanca y "desierto" a territorios ya habitados por numerosas comunidades de pueblos originarios Mapuces y Tehuelches.

La reinterpretación de la historia en los términos que propone la FL latinoamericana, en este punto, se vuelve ontológicamente fundante, en tanto remite a una hermenéutica que cuestiona el origen mismo de nuestro ser como resultado de un proceso histórico de aculturación. Retomando las palabras de Octavio Paz, Dussel nos dice sobre 1492:

... [el] hijo de Malinche (la india que traiciona su cultura) y de Cortés (el padre de la conquista y las virtudes del Estado dependiente, porque Cortés no es el Rey), “no quiere ser ni indio, ni español. Tampoco quiere descender de ellos. Los niega. Y no se afirma en tanto que mestizo, sino como abstracción: es un hombre. Se vuelve hijo de la nada...”. (Dussel, 1980, p. 15-16)

Si la primera relación que establecemos como sujetos es ética y se da a través del encuentro cara-a-cara, la pedagógica establecida como relación de dominación genera la idea de una procedencia de la nada, lineal y unívoca en tanto construida por un solo discurso y una sola perspectiva. La idea de un origen que niega y omite todo relato de violencia originaria y de opresiones, produce una base identitaria débil. No hay Historia ni relaciones de poder que la enmarquen ni problematicen. Se profundiza así la idea de que somos sujetos provenientes de la nada: "Antes del hijo mestizo, erraron por América huérfanos amerindianos, objeto de la dominación pedagógica: los conquistadores 'vienen y extienden su poder sobre los huérfanos de madre, sobre los huérfanos de padre”' (Dussel, 1980, p. 17).

Sobre este punto, Dussel llama nuestra atención sobre los clásicos relatos de la Pedagogía moderna, que generalmente recurre a la imagen de la tábula rasa a la hora de definir al sujeto. Desde el empirismo más básico, hasta el ideal de hombre huérfano que plantea Rousseau en el Emilio, parten de la idea de un pasado nulo, inexistente, enfocándose en proyectos educativos que miran siempre hacia adelante, con todo un mundo de sentidos por "construir". 
Es en este momento en el que la propuesta de la Pedagógica dusseliana pone de relieve, para que puedan ser sometidos a crítica, los argumentos histórico-filosóficos fundantes de estas relaciones de dominio desde una filosofía crítica Latinoamericana. Dentro de la arquitectónica dusseliana, la Pedagógica constituye el pasaje de la erótica a la política (Dussel, 1980, p. 15). Pero para profundizar qué significa que la pedagógica es la convergencia de lo erótico y político, Dussel propone la siguiente analogía:

El padre (la imago del padre y la madre, también como maestro, médico, profesional, filósofo, cultura, Estado, etcétera) prolonga su falocracia como agresión y dominación del hijo: el filicidio. La muerte del hijo, el niño, la juventud, las generaciones recientes por parte de las gerontocracias o burocracias es física (en la primera línea de los ejércitos o los sacrificios humanos), simbólica o ideológica, pero es siempre un tipo de alienación, dominación, aniquilación de Alteridad. (Dussel, 1980, p. 15)

Volvamos a la historia de Inakayal, y otrxs caciques cuyo destino no fue tan trágico, pero que también sufrieron este fraticidio y filicidio. Los niños son separados de sus padres y sus madres. Las mujeres y las niñas son repartidas en las casas de los militares como servidumbre. En muchos casos, como en la provincia de Buenos Aires, esta entrega se realiza en las plazas públicas. En palabras del historiador argentino Osvaldo Bayer compartimos el siguiente relato:

El diario El Nacional, de Buenos Aires, expresa en su edición del 31 de diciembre de 1878: "Llegan los indios prisioneros con sus familias. La desesperación, el llanto no cesan. Se les quitan a las madres sus hijos para en su presencia regalarlos, a pesar de los gritos, los alaridos y las súplicas que hincadas y con los brazos al cielo dirigen las mujeres indias. En aquel marco humano, unos se tapan la cara, otros miran resignadamente al suelo, la madre aprieta contra el seno al hijo de sus entrañas, el padre se cruza por delante para defender a su familia de los avances de la civilización". Esta crónica de esos días lo dice todo. (Bayer, 2014)

Los niños son llevados a escuelas donde son evangelizados y se les enseñan oficios y trabajos de distinta complejidad. "La muerte del hijo, del niño", implica la posterior negación de la juventud de la cultura y la historia que le eran propias antes del dominio del llamado conquistador. Es así como la falocracia erótica por mediación del filicidio pedagógico culmina en el fratricidio político (Dussel, 1980, p. 15).

Es en este sentido que la función concreta de la Pedagógica en un esquema de praxis de liberación estará necesariamente relacionada con la vuelta al protagonismo de las voces de la mujer como base de la pedagógica amerindia (porque la pedagógica hispánica es la del padre), las voces de los jóvenes ante la gerontocracia, y las voces de lxs niñxs ante el filicidio.

La docencia que hoy ejerzo como mi singular aporte en la transformación de nuestras realidades me hace repensarme dentro de esas relaciones generacionales de dominio que evidentemente se siguen planteando desde una continuidad de negaciones e invisibilizaciones. Con muchos interrogantes aún por responder, no puedo dejar de preguntarme: ¿Qué nos impide dimensionar los niveles de violencia que tuvieron que vivir nuestros pueblos originarios, conformados ya en naciones, frente a la llegada de los ejércitos invasores cuyo único interés era el dominio económico y político? ¿Cómo nos sigue llegando, a partir de lo que ofrecen nuestros discursos educativos, el relato acerca de nuestros orígenes?

Se nos impone un mito civilizatorio, al decir de Dussel, se nos crea un relato que realza las bondades de un supuesto progreso que solo oculta la cruda y cruel violencia vivida por cada genocidio, enseñado en los relatos oficiales como conquistas. 
La imposición de un relato fundador ajeno nos construye y nos fija desde lo que Enrique Dussel plantea como exterioridad. Esta imposición interpretativa de los hechos promovida en los diferentes niveles de nuestros sistemas educativos, se instala así política e ideológicamente en nuestras construcciones identitarias como el momento que da inicio a la civilización negando toda la otra historia, que también somos.

Desde un posicionamiento geopolítico latinoamericano, me dejo interpelar por la pregunta que realizara José Martí acerca de cómo somos, por fuera de lo que históricamente nos dijeron que éramos. ¿Cómo somos? ¿Quiénes somos? Preguntas filosóficas si las hay. Exigencia a dar cuenta del ser. Necesidad de decirnos, de nombrarnos con voz propia, de sabernos Otrxs. Negadxs, invisibilizadxs, encubiertxs y, por eso mismo, con todo por decir.

\section{Inakayal y cómo seguimos...}

Conocí la historia de Inakayal en un congreso universitario de Investigación Educativa, no podía ser de otra manera. Vi su foto expuesta en una muestra fotográfica que formaba parte del congreso. Vi su rostro y los de su familia, sus lugares de vida y de muerte, como muchxs otrxs ya lo habían hecho. Expuesto. Expuestxs ante todas nuestras miradas.

Me surgió preguntarme: ¿Qué lugares siguen ocupando estos conocimientos en nuestras instituciones educativas? Tal como afirma Dussel en la Pedagógica latinoamericana todo "proyecto pedagógico de dominación siempre es fruto de violencia, de conquista, de represión del Otro como otro" (Dussel, 1980, p. 73). Estas palabras tomaron otro sentido cuando luego de conocer la historia de Inakayal me doy cuenta que jamás había escuchado siquiera de su existencia en ninguna de las instancias de mi educación formal, pero sí podía dar cuenta de quién era el Perito Moreno, por ser un militar que goza de mucho reconocimiento en Argentina y es reivindicado inclusive como prócer. Eso sí me lo enseñó la escuela.

Pienso en los relatos pedagógicos que me construyeron. Como tarea de ruptura y muerte de la cotidianeidad, tal como nos exige la FL, me vuelvo a mi comunidad. Descubro que muchas de las calles principales de mi ciudad se llaman como los militares responsables de la muerte y captura de Inakayal, y tantxs otrxs. Ninguna calle rememora a Inakayal, ni homenajea su memoria, siquiera por respeto a su dolor como hermano asesinado, como vergüenza ante el fratricidio.

3. Kimeltufe/educadora. Autoridad política y espiritual del pueblo mapuce en Newken, Argentina.
Quise saber y pregunté a una amiga, referente de las comunidades mapuces urbanas del territorio que habito. Siempre generosa en su saber, Pety ${ }^{3}$ me contó más sobre Inakayal y también sobre nuestras historias. Me contó que Inakayal era su nombre, su identidad. Que los nombres mapuces están generalmente conformados por palabras que evocan fuerzas de la naturaleza o nombres de animales, que conectan a la persona con su procedencia territorial y ancestral. Que generalmente es uno y compuesto. Inakayal, tenía la marca de la conquista, previa a la que terminó con su vida, en su propio nombre: lo llamaron Modesto.

Pienso en Inakayal. Las imágenes de su rostro me acompañarán por largo tiempo. Seguí buscando información, como una forma de encontrar explicaciones al horror. Quizás también como la forma que me enseñaron para conocer. Encontré varias notas que relataban cómo el 19 de abril de 1994 parte de los restos de Inakayal fueron entregados a su comunidad en la ciudad de Tecka, Chubut. Y digo parte de los restos, porque como un dolor que aún no cesa, en el año 2006 estudiantes de antropología que continuaban 
las tareas de identificación, encontraron el corazón de Inakayal. Lloré al leer esta noticia. Lloré porque, tal como sostiene Dussel, detrás de cada rostro hay alguien. Lloré porque sentí la voz de Inakayal aún exigiendo justicia, desde la exterioridad que la historia suele materializar en muchas formas de olvido.

Recordé nuestra conversación con Pety acerca de cómo la imposición de nombres funcionó como otra forma de opresión, otra forma de dominación. Recordé los reclamos de mi madre, a su abuela mapuce que no le enseñó hablar mapudungún, el idioma mapuce. Recordé el reclamo de mi padre de las no respuestas al preguntar sobre sus orígenes. Demasiados silencios. Silencios que desde una pedagógica de la liberación es necesario darles voces, rostros y conectarlos hasta sentirnos parte de esas historias negadas, aún por nosotrxs mismxs, tanto en el plano familiar, como en el plano institucional político.

Inakayal es un nombre mapuce, me dijo Pety, y la raíz de esa palabra es Ina, que significa el que sigue, el que continúa. Al escuchar esas palabras, en medio de tanto dolor, una leve esperanza me atravesó, y me sostuvo en la certeza de saber que este es recién un inicio en la búsqueda incansable de concretar proyectos Pedagógicos Liberadores basados en la justicia y en el reconocimiento ético y político de todx Otrx. Esxs Otrxs que la pedagogía moderna nos negó, negando sus rostros, negando sus nombres, pero que siguen aquí. 


\section{- Referencias bibliográficas}

" Bayer, O. (8 de noviembre de 2014). Página 12, Contratapa. Recuperado de <https://www.pagina12.com.ar/diario/contratapa/13-259378-2014-11-08.html>.

»Cardoso F. H. y Faletto E. (1969). Dependencia y Desarrollo en America Latina. Ciudad de México: Siglo XXI.

»Dussel, E. (1977a). Filosofía de la liberación. Bogotá: Nueva América.

»__. (1977b). Introducción a una filosofía de la liberación Latinoamericana. Bogotá: Nueva América.

》___ (1980). La pedagógica Latinoamericana. Bogotá: Nueva América.

»__. (1992). Historia de la iglesia en América Latina: medio milenio de coloniaje y liberación (1492-1992). Madrid: Mundo Negro-Esquila Misional.

»__ (1994). 1492: el encubrimiento del otro. Hacia el origen del mito de la modernidad. La Paz: Facultad de Humanidades y Ciencias de la Educación, UMSA - Plural.

»__. (1995). Introducción a la filosofía de la liberación. Bogotá: Nueva América.

»__. (1998). Ética de la Liberación en la Edad de la Globalización y de la Exclusión. México: UNAM/Itzapalapa - Fondo de Cultura Económica.

"García Ruíz, P. (2014). Geopolítica de la alteridad: Levinas y la filosofía de la liberación de E. Dussel. Isegoría. Revista de Filosofía Moral y Política, (51), 777-792.

» Gutiérrez, G. (1971). Teología de la liberación: Perspectivas. Lima: Sígueme.

"Moyano, A. (2018). A ruego de mi superior cacique Antonio Modesto INAKAYAL. Viedma: Fondo Editorial Rionegrino.

\section{Normativa}

»Congreso de la Nación Argentina. (21 de noviembre de 2010). [Ley 25517 de 2010].

\section{Nadia Heredia}

Doctoranda en Educación, Facultad de Ciencias de la Educación, Universidad Nacional del Comahue, Neuquén, Argentina. Especialista en Investigación Educativa, Facultad de Ciencias de la Educación/ Escuela 'Marina Vilte' CTERA, Universidad Nacional del Comahue. Licenciada y profesora en Filosofía, Facultad de Humanidades, Universidad Nacional del Comahue. Correo electrónico: nadiaheredia@gmail.com 